\title{
Correction: Mismatch negativity as EEG biomarker supporting CNS drug development: a transnosographic and translational study
}

Simon Loiodice (D, Wilhelmus H. Drinkenburg, Abdallah Ahnaou (D, Andrew McCarthy, Geoffrey Viardot, Emilie Cayre, Bertrand Rion, Valérie Bertaina-Anglade, Marsel Mano, Philippe L'Hostis, Christophe Drieu La Rochelle,

Martien J. Kas (1) and Philippe Danjou

Correction to: Translational Psychiatry https://doi.org/10.1038/s41398-021-01371-1

published online 29 April 2021
The original version of this article unfortunately contained a mistake in an author name. The correct name is Abdallah Ahnaou. The original article has been corrected.

Published online: 10 May 2021 